\title{
Perda de solo e água sob integração lavoura-floresta e em sucessão soja-milho
}

\author{
Cornélio Alberto Zolin ${ }^{(1)}$, Janaina Paulino(2), Eduardo da Silva Matos ${ }^{(1)}$, Ciro Augusto de Souza Magalhães ${ }^{(1)}$, \\ Frederico Terra de Almeida(2), Adilson Pacheco de Souza(2) e Rafael Mingoti( ${ }^{(3)}$
}

\begin{abstract}
(1)Embrapa Agrossilvipastoril, Rodovia MT-222, Km 2,5, CEP 78550-970 Sinop, MT, Brasil. E-mail: cornelio.zolin@embrapa.br, eduardo.matos@embrapa.br, ciro.magalhaes@embrapa.br (2)Universidade Federal de Mato Grosso, Instituto de Ciências Agrárias e Ambientais, Avenida Alexandre Ferronato, № 1.200, Setor Industrial, CEP 78557-267 Sinop, MT, Brasil. E-mail: eng_janaina@yahoo.com.br, fredterra@ufmt.br, pachecopgid@yahoo.com.br ${ }^{(3)}$ Embrapa Gestão Territorial, Avenida Soldado Passarinho, № 303, Fazenda Chapadão, CEP 13070-115 Campinas, SP, Brasil. E-mail: rafael.mingoti@embrapa.br
\end{abstract}

Resumo - O objetivo deste trabalho foi avaliar, em condição de chuva natural, a perda de solo e água em sistemas de produção com integração lavoura-floresta ou com sucessão soja-milho. $\mathrm{O}$ experimento foi realizado em Latossolo Vermelho-Amarelo com textura muito argilosa, em uma região de transição Cerrado/Amazônia. Os seguintes usos e coberturas do solo foram avaliados: sistema integração lavoura-floresta; lavoura com sucessão soja-milho+braquiária; e solo descoberto. As lavouras foram cultivadas em sistema plantio direto em sucessão soja-milho+braquiária, todos os anos, independentemente do sistema de produção. A perda de solo por erosão hídrica, nos três anos avaliados, foi de $0,215 \mathrm{Mg} \mathrm{ha}^{-1}$ por ano, no sistema integração lavoura-floresta, e de 0,753 $\mathrm{Mg} \mathrm{ha}^{-1}$ por ano na lavoura com sucessão soja-milho. Estes valores situaram-se abaixo do limite de tolerância, que é de 11,1 Mg ha-1 por ano, e os menores valores observados com a integração lavoura-floresta apontam para o elevado potencial conservacionista desse sistema.

Termos para indexação: conservação do solo, erosão hídrica, escoamento superficial, plantio direto, recursos hídricos, sistemas de integração.

\section{Soil and water losses under crop-forest integration and in soybean-corn succession}

\begin{abstract}
The objective of this work was to evaluate, under conditions of natural rainfall, the soil and water losses in crop-forest integration systems or in soybean-corn succession. The experiment was carried out in a clayey Latossolo Vermelho-Amarelo (Oxisol), in a Cerrado/Amazon transition region. The following land use and soil covers were evaluated: crop-forest integration system; soybean-corn+brachiaria succession system; and bare soil. Crops were cultivated under no-tillage in soybean-corn+brachiaria sucession, every year, regardless of the production system. In the three years of evaluation, soil losses by hydraulic erosion were of $0.215 \mathrm{Mg} \mathrm{ha}^{-1}$ per year, in the crop-forest integration system, and of $0.753 \mathrm{Mg} \mathrm{ha}^{-1}$ per year, in the soybeancorn succession system. These values were below the tolerance limit, which is of $11.1 \mathrm{Mg} \mathrm{ha}^{-1}$ per year, and the lowest values for crop-forest integration point towards the great conservation potential of this production system.
\end{abstract}

Index terms: soil conservation, hydraulic erosion, surface water runoff, no-tillage, water resources, integration systems.

\section{Introdução}

A erosão hídrica é um dos principais fatores que contribuem para a diminuição da produtividade, pois pode acarretar a degradação dos solos agrícolas (Carvalho et al., 2007). As perdas de água e solo por escoamento superficial dependem da precipitação, topografia, cobertura vegetal e das práticas conservacionistas utilizadas nos sistemas de produção (Guadagnin et al., 2005). Entre esses fatores, a cobertura vegetal e as práticas conservacionistas podem ser ajustados e contribuir para a redução da erosão hídrica em sistemas agrícolas.

A cobertura vegetal exerce importante papel na cobertura do solo, ao reduzir o impacto das gotas da chuva (Martins et al., 2003; Cândido et al., 2014); além disso, o incremento de matéria orgânica do solo e o sistema radicular contribuem para a melhoria de atributos físicos do solo, relacionados à infiltração de água e à agregação, e, consequentemente, contribuem para a redução da erodibilidade do solo (Wohlenberg 
et al., 2004; Conte et al., 2011). O resíduo das culturas, por sua vez, dissipa a energia cinética das gotas da chuva, ao evitar ou minimizar a desagregação inicial do solo, e serve como barreira física à ação cisalhante e de transporte da enxurrada (Guadagnin, et al., 2005; Amaral et al., 2008).

Estudos têm mostrado a existência de uma relação direta das perdas de solo com a erosão, em culturas agrícolas (Bertol et al., 2001; Engel et al., 2007), pastagens (Panachuki et al., 2006; Oliveira et al., 2014) e eucalipto (Martins et al., 2003, 2010; Brito et al., 2005; Pires et al., 2006). Outros trabalhos também evidenciaram a contribuição das práticas conservacionistas para a redução da perda de água e solo por escoamento superficial (Bertol et al., 2001; Albuquerque et al., 2002; Lanzanova et al., 2013). Porém, não há relatos, na literatura, quanto ao efeito sinérgico da integração lavoura-floresta sobre a redução no escoamento de água na superfície do solo e, consequentemente, sobre a perda de solo e água em consequência de chuvas naturais. Além disso, a região norte mato-grossense está inserida em um contexto de rápida mudança de uso e ocupação do solo, que pode resultar em sérios problemas ambientais.

O objetivo deste trabalho foi avaliar, sob condição de chuva natural, a perda de solo e água em área com integração lavoura-floresta, lavoura com sucessão soja-milho e área descoberta (solo exposto), em Latossolo Vermelho-Amarelo com textura muito argilosa, em uma região de transição Cerrado/ Amazônia.

\section{Material e Métodos}

A pesquisa foi desenvolvida no Município de Sinop, MT, no campo experimental da Embrapa

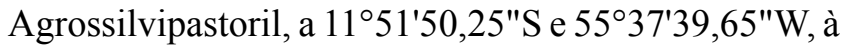
altitude média de $364 \mathrm{~m}$. O solo no local do experimento é classificado como Latossolo Vermelho-Amarelo, com textura argilosa com horizonte A moderado (Embrapa, 2013), cujas camadas de 0,0-0,20 (horizonte A) e 0,20-1,00 m(horizonteB)apresentam, respectivamente, 51 e $56 \%$ de argila, com relevo suave-ondulado. O clima da região é Aw (clima tropical), segundo a classificação de Köppen-Geiger, com médias anuais de temperatura e precipitação pluvial de $24,7^{\circ} \mathrm{C}$ e 1.974 $\mathrm{mm}$, respectivamente (Souza et al., 2013).
A área experimental começou a ser desmatada em 1984, para a produção de mandioca (Manihot esculenta Crantz) (Araujo et al., 2009), com término do desmatamento na década de 2000. De acordo com Diel et al. (2014), no início da década de 1990, a área passou a ser cultivada com arroz (Oryza sativa L.) e, posteriormente, com soja [Glycine $\max$ (L.) Merr.]. De 2002 a 2007, ela foi cultivada com soja e milho safrinha (Zea mays L.), no sistema convencional. Nas safras 2007/2008 e 2008/2009, foram realizadas sucessões de soja e algodão (Gossypium hirsutum L.). $\mathrm{Na}$ safra 2010/2011, a área permaneceu em pousio. Para instalação do experimento, foram realizadas operações de descompactação (subsolagem a $0,40 \mathrm{~m}$ e gradagem leve), para uniformizar a estrutura do solo. Após estas operações, efetuadas entre setembro e outubro de 2011 , foram realizadas as atividades que se seguem e que constituem os seguintes tratamentos empregados em cada parcela: ILF, sistema integração lavoura-floresta, com o componente arbóreo clone h13 de Eucalyptus urograndis, em consórcio com soja (1. ${ }^{\mathrm{a}}$ safra) e milho (sucessão, 2. ${ }^{a}$ safra); lavoura, lavoura com sucessão de soja (1. ${ }^{a}$ safra) e milho (sucessão, 2. ${ }^{a}$ safra)+braquiária; e $\mathrm{Sd}$, solo descoberto.

As densidades do solo, determinadas a partir da coleta de anéis volumétricos nas áreas de estudo, foram: $1,16 \mathrm{Mg} \mathrm{m}^{-3}$ (ILF) e $1,17 \mathrm{Mg} \mathrm{m}^{-3}$ (solo descoberto e lavoura). As declividades médias das parcelas foram de $1,5 \%$ para os três tratamentos.

Os preparos do solo e a semeadura das culturas foram feitos no sentido perpendicular ao declive. Ao longo dos três anos de avaliação, a cultura da soja foi semeada com espaçamento entre linhas de 0,45 $\mathrm{m}$ e aproximadamente 17 plantas por metro linear e após a colheita, a cultura do milho foi semeada com espaçamento entre linhas de $0,45 \mathrm{~m}$ e aproximadamente 3,0 plantas por metro linear.

com espaçamento de $0,50 \mathrm{~m}$ entre linhas e 20 plantas por metro linear e após a colheita, a cultura do milho foi semeada em linhas espaçadas de $0,50 \mathrm{~m}$ entre si, com distância entre plantas de $0,20 \mathrm{~m}$.

A unidade experimental constituiu-se de uma parcela com calhas tipo Wischmeier (1959), com dimensões de $22,00 \times 6,00 \mathrm{~m}\left(132 \mathrm{~m}^{2}\right)$, delimitada superior e lateralmente por chapas galvanizadas de $3,00 \times 0,30 \mathrm{~m}$, cravadas no solo até aproximadamente $0,15 \mathrm{~m}$. O comprimento da parcela acompanhou o sentido do declive do terreno. $\mathrm{Na}$ extremidade inferior foram 
instaladas calhas coletoras do escoamento, o qual era conduzido às caixas de coleta em cano de PVC. O sistema de coleta era composto por duas caixas d'água com capacidade de $1.000 \mathrm{~L}$. Entre as caixas de coleta, foi instalado um sistema divisor/transferidor tipo Geib, com 11 janelas, que conduzia para a segunda caixa 1/11 do escoamento excedente proveniente da primeira caixa.

As coletas para determinação da perda de solo e água foram realizadas após os eventos de chuva que geraram escoamento superficial, entre novembro de 2012 e maio de 2015. A fim de quantificar a perda de solo e água, amostras do escoamento e dos sedimentos foram retiradas das caixas d'água. Os sedimentos grosseiros foram retidos em um saco de algodão de 50 $\mathrm{L}$, instalado na primeira caixa. Após a homogeneização do escoamento presente nas caixas, foram feitas coletas de alíquota de $1 \mathrm{~L}$, que foram levadas para o laboratório e submetidas à filtração com papel-filtro quantitativo, para a determinação dos sedimentos em suspensão (Carvalho et al., 2000). O material filtrado e os sedimentos grosseiros foram secos em estufa a $105^{\circ} \mathrm{C}$, para a determinação da massa do material seco.

$\mathrm{Na}$ determinação da erosividade da chuva, utilizaram-se os dados pluviométricos mensais obtidos no local do experimento durante o período das coletas. Posteriormente, calculou-se a erosividade mensal $\left(\mathrm{EI}_{30 \mathrm{~m}}\right)$ de acordo com a equação proposta por Almeida et al. (2012).

A tolerância de perda de solo por erosão hídrica foi calculada por meio da equação, utilizada por Lombardi Neto \& Bertoni (1975), como T $=$ h r $1.000^{-1}$, em que: $\mathrm{T}$ é a tolerância de perda de solo ( $\mathrm{mm} / \mathrm{ano})$; h é a profundidade efetiva do solo (mm), limitada a 1.000 $\mathrm{mm}$; e r é o quociente que expressa o efeito da relação textural entre os horizontes $\mathrm{B}$ e A, na ponderação da perda de solo $\left(\mathrm{g} \mathrm{kg}^{-1} / \mathrm{g} \mathrm{kg}^{-1}\right)$.

A normalidade dos dados foi testada pelo teste de Shapiro-Wilk. Como os resultados foram não paramétricos, aplicou-se o teste de Kruskal-Wallis, para verificar se havia diferença entre os conjuntos de dados. Após constatar diferença significativa, executouse o teste de Wilcoxon, para verificar quais tratamentos diferiram entre si, e sua devida significância.

\section{Resultados e Discussão}

Os dados de precipitação pluvial e erosividade mensal, coletados na área experimental de novembro de 2012 a julho de 2015, foram separados entre os seguintes períodos: de outubro de 2012 a setembro de 2013 (ano 2012/2013), outubro de 2013 a setembro de 2014 (ano 2013/2014), e outubro de 2014 a julho de 2015 (ano 2014/2015) (Figura 1).

Nos anos 2012/2013, 2013/2014 e 2014/2015, os totais precipitados foram de 2.210, 2.269 e $1.730 \mathrm{~mm}$ respectivamente. Em geral, as maiores precipitações ocorreram de janeiro a março nos três anos, com exceção de dezembro de 2013, quando ocorreu a maior precipitação mensal da série apresentada $(676 \mathrm{~mm})$, em que a erosividade chegou a $4.557 \mathrm{MJ} \mathrm{mm} \mathrm{ha}^{-1} \mathrm{~h}^{-1}$ por mês. No presente trabalho, 16.092 e 16.142 MJ $\mathrm{mm} \mathrm{ha} \mathrm{h}^{-1} \mathrm{~h}^{-1}$ por ano de erosividade foram encontrados nos anos de 2012/2013 e 2013/2014, respectivamente, valores estes bem semelhantes aos encontrados por Almeida et al. (2012), que verificaram no Município de Vera, MT, próximo à área estudada, valores de erosividade de 16.220 MJ mm ha ${ }^{-1} \mathrm{~h}^{-1}$ por ano. No entanto, no ano de 2014/2015, no presente trabalho, a erosividade apresentou valor mais baixo, de $14.376 \mathrm{MJ}$ $\mathrm{mm} \mathrm{ha} \mathrm{h}^{-1} \mathrm{~h}^{-1}$ por ano, assim como menor precipitação.

Os dados de perda de água e solo foram submetidos ao teste não paramétrico de Kruskal-Wallis, que foi significativo a $1 \%$ de probabilidade. Assim, aplicou-se o teste de Wilcoxon, para testar os pares (Tabela 1).

Pode-se observar que houve diferença significativa entre os tratamentos, quanto à perda de água e de solo, em que $\mathrm{Sd}>$ Lavoura $>$ ILF (Tabela 2).

A perda de água foi superior no tratamento $\mathrm{Sd}$ (Tabela 2); lavoura e ILF apresentaram valores menores, com perda maior no tratamento lavoura e menor no ILF. Observa-se, ainda, que os menores valores de perda de água ocorreram no terceiro ano de coleta, em que a erosividade foi de $14.376 \mathrm{MJ} \mathrm{mm}$ $\mathrm{ha}^{-1} \mathrm{~h}^{-1}$, ou seja, inferior à de 2012/2013 (16.092 MJ $\mathrm{mm} \mathrm{ha}^{-1} \mathrm{~h}^{-1}$ ) e 2013/2014 (16.142 MJ mm ha-1 $\mathrm{h}^{-1}$ ). Amaral et al. (2008) relataram distribuição temporal das chuvas, tanto quanto à perda de solo quanto à de água, pois a erosividade pode variar no tempo, em consequência de variações da intensidade, duração e frequência das precipitações.

A perda de água no Sd resultou em uma média de $381 \mathrm{~mm}$. Silva et al. (2005) e Carvalho et al. (2007) estudaram as perdas de água em um Latossolo Vermelho distroférrico e encontraram perdas de 113 e $298 \mathrm{~mm}$, valores inferiores aos encontrados no presente trabalho; o mesmo fato ocorreu nas observações de

Pesq. agropec. bras., Brasília, v.51, n.9, p.1223-1230, set. 2016 DOI: 10.1590/S0100-204X2016000900022 
Pires et al. (2006), que encontraram $86 \mathrm{~mm}$ de perda de água em Latossolo Vermelho-Amarelo. As menores perdas observadas por Silva et al. (2005), Pires et al. (2006) e Carvalho et al. (2007) podem ter ocorrido pelo fato de a erosividade das chuvas ter variado de 4.865 a $8.102 \mathrm{MJ} \mathrm{mm} \mathrm{ha}^{-1} \mathrm{~h}^{-1}$ por ano, valores menores do que a erosividade média do presente trabalho, de 15.537 $\mathrm{MJ} \mathrm{mm} \mathrm{ha}^{-1} \mathrm{~h}^{-1}$ por ano.

As perdas de água foram reduzidas em $86 \%$ na lavoura e, no ILF, em 91\%, em comparação ao solo descoberto. Albuquerque et al. (2002), Silva et al. (2005) e Pires et al. (2006) também observaram reduções significativas de perdas de água, nos tratamentos que continham cobertura vegetal. Hernani et al. (1999) e Schick et al. (2000) relatam que há mecanismos "preferenciais" de perdas, em razão da proteção do solo oferecida pela cultura. Outros autores, como Bertol et al. (1987) e Mello et al. (2003), informam que as perdas de água da chuva, na forma de enxurrada, são geralmente menos influenciadas pelo efeito da cobertura; porém, no presente trabalho, o que se observou foi redução significativa das perdas de água em Lavoura e ILF, como citado anteriormente. Martins et al. (2003), Brito et al. (2005) e Pires et al. (2006) associam menores perdas de água em floresta ao efeito sinérgico da interceptação da chuva pelo dossel da floresta com o acúmulo de restos vegetais e com a melhor estruturação do solo decorrente do sistema radicular das árvores. No presente trabalho, estes fatores podem estar ligados à menor perda de água ocorrida no sistema ILF. Dados de resistência à penetração e densidade do solo mostram que onde foi preparado o sulco de plantio de eucalipto, o solo apresentava alta macroporosidade, a qual contribui para maior infiltração de água e, consequentemente, menor perda de água.

Entre os meses, nos três anos, não se observou predominância de perda de água em um mês específico (Figura 2), assim como da precipitação e da erosividade ao longo dos anos, porém, as menores perdas no ano de 2014/2015 corroboraram as menores precipitação e erosividade ocorridas nesse ano.

Analisando-se os três anos, é possível perceber que a perda de solo (Tabela 2) foi menor no terceiro ano de avaliação, assim como a perda de água. Nesse ano, a precipitação e a erosividade foram inferiores às dos demais anos, e isso pode ter influenciado as menores perdas. Para o ILF, a redução da erosividade no terceiro ano foi bastante significativa e pode estar associada ao aumento da copa do eucalipto, ao longo dos anos,

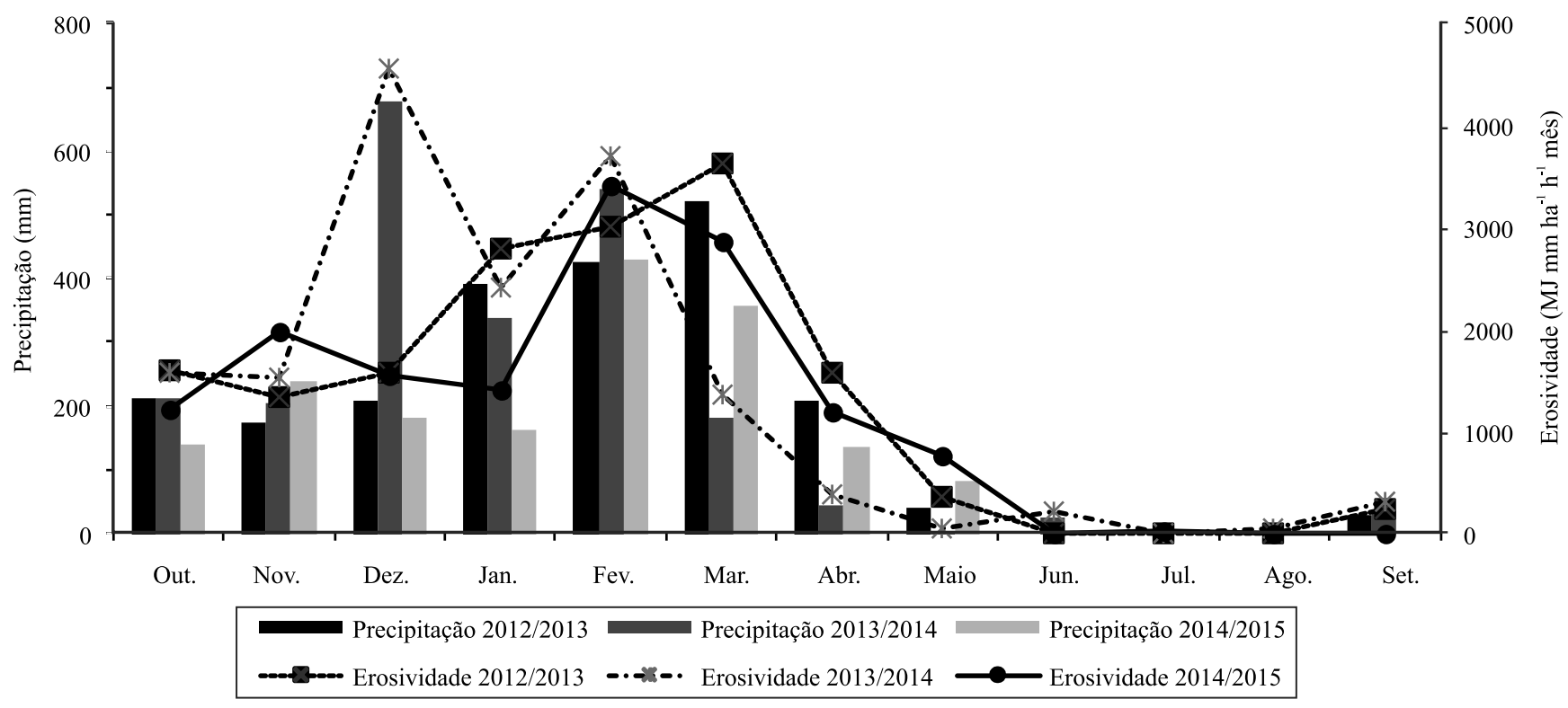

Figura 1. Precipitação pluvial e erosividade mensal de novembro de 2012 a julho de 2015. 
que reduziu o impacto direto das gotas de chuva no solo (Martins et al., 2010). Lima (1996) encontrou perdas de água e solo maiores no primeiro ano do que no quarto ano de cultivo. Outro ponto importante é o processo de estabilização gradual do solo, após a mobilização ocorrida durante o primeiro ano, em áreas recém-implantadas com eucalipto, Martins et al. (2003) observaram perda de solo próxima à da condição de solo descoberto e atribuíram esse efeito ao tempo necessário para a acomodação da superfície, pelo revolvimento do solo após a implantação do experimento.

Conforme mencionado anteriormente, dados de resistência à penetração e da densidade do solo, no terceiro ano de avaliação do ILF, mostraram que, onde foi preparado o sulco de plantio de eucalipto, o solo apresentou alta macroporosidade, que que esta pode ter contribuído para a menor perda de solo. O limite de tolerância de perda de solo, encontrado para a área de estudo, foi de $1,11 \mathrm{~mm}$ por ano, ou seja, $11,1 \mathrm{Mg} \mathrm{ha}^{-1}$ por ano. Observando-se as perdas anuais em todos os sistemas avaliados, verifica-se que o Lavoura e o ILF apresentaram valores inferiores ao limite de tolerância, o que mostra que a cobertura do solo proporcionada pelas culturas reduziu significativamente as perdas

Tabela 1. Pares de usos e coberturas do solo, pelo teste de Wilcoxon.

\begin{tabular}{ccc}
\hline Sd x Lavoura** & $\begin{array}{c}\text { Perda de solo } \\
\text { Sd x ILF** }\end{array}$ & ILF x Lavoura** \\
\hline & Perda de água & \\
Sd x Lavoura** & Sd x ILF** & ILF x Lavoura* \\
\hline
\end{tabular}

**e*Significativo a 1 e $5 \%$ de probabilidade, respectivamente, pelo teste de Wilcoxon. Sd, solo descoberto e iLF, integração lavoura-floresta.

Tabela 2. Perda anual de água e solo nos sistemas avaliados.

\begin{tabular}{|c|c|c|c|}
\hline \multirow[t]{2}{*}{ Ano } & \multicolumn{3}{|c|}{ Usos e coberturas de solo } \\
\hline & Solo descoberto & ILF & Lavoura \\
\hline & \multicolumn{3}{|c|}{ Perda de água (mm) } \\
\hline $2012 / 2013$ & 691,26 & 35,29 & 49,10 \\
\hline $2013 / 2014$ & 331,14 & 39,79 & 78,45 \\
\hline $2014 / 2015$ & 121,54 & 33,35 & 29,68 \\
\hline \multirow[t]{2}{*}{ Total } & $1.144,34$ & 108,43 & 157,23 \\
\hline & \multicolumn{3}{|c|}{ Perda de solo $\left(\mathrm{Mg} \mathrm{ha}^{-1}\right)$} \\
\hline $2012 / 2013$ & 17,116 & 0,235 & 0,827 \\
\hline $2013 / 2014$ & 17,561 & 0,325 & 0,756 \\
\hline $2014 / 2015$ & 11,989 & 0,087 & 0,677 \\
\hline Total & 146,666 & 0,647 & 2,26 \\
\hline
\end{tabular}

ILF, integração lavoura-floresta.
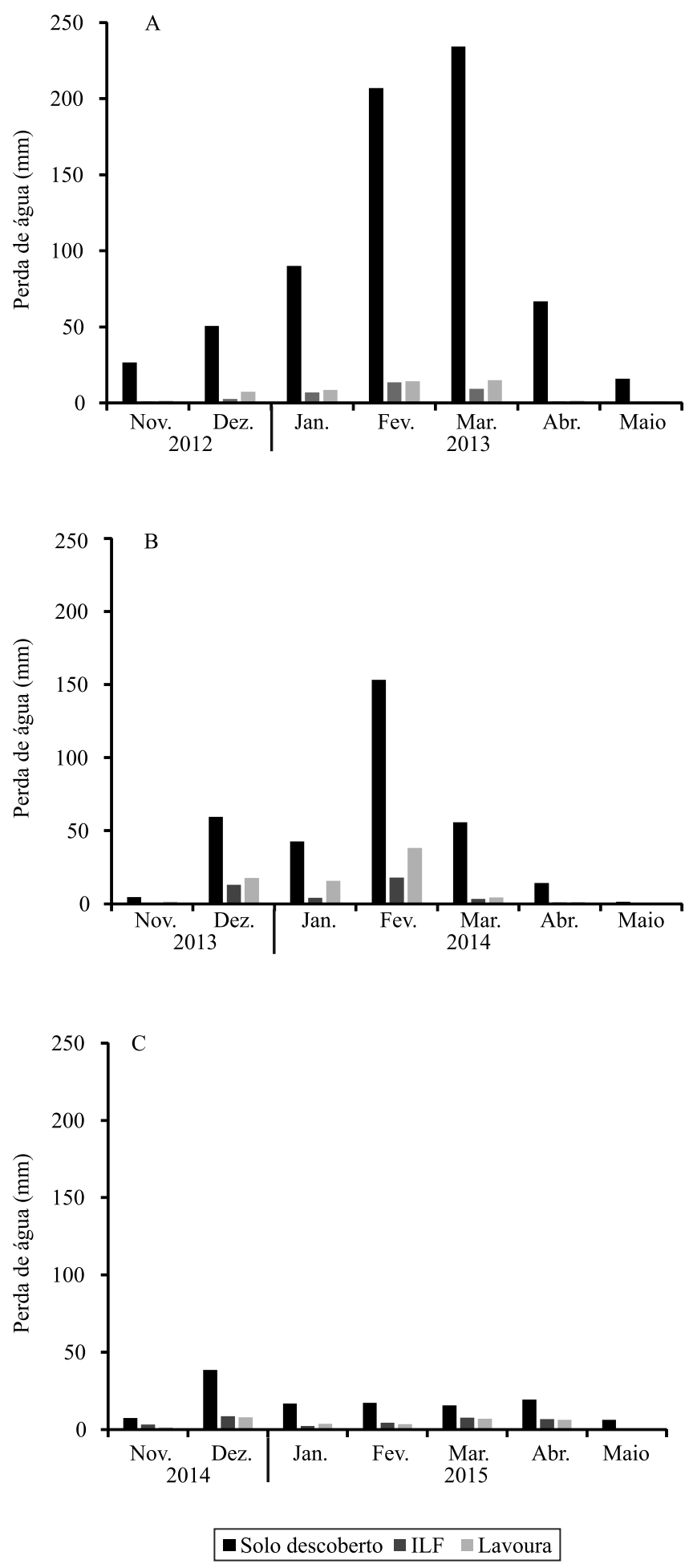

Figura 2. Perda de água $(\mathrm{mm})$ mensal ocorrida em 2012/2013 (A), 2013/2014 (B) e 2014/2015 (C), nos sistemas: ILF, sistema integração lavoura-floresta, lavoura e solo descoberto.

Pesq. agropec. bras., Brasília, v.51, n.9, p.1223-1230, set. 2016 DOI: 10.1590/S0100-204X2016000900022 
de solo, cujos valores ficaram abaixo do limite de tolerância. Bertol et al. (1987), Schick et al. (2000) e Guadagnin et al. (2005) encontraram maiores perdas em solo descoberto do que em áreas cultivadas e explicam que tal resultado é esperado, pois, no solo descoberto, há maior desagregação e transporte de solo por salpicamento das partículas provocado pelo impacto das gotas de chuva. Verificou-se que, o solo descoberto apresentou os maiores valores de perda de solo que, além disso, estavam acima do limite de tolerância, conforme também observado por Silva et al. (2005) e Carvalho et al. (2007) em Latossolo Vermelho distroférrico típico.

Entre os sistemas com cultivo, o ILF apresentou menor perda de solo do que o Lavoura e com valores inferiores aos do limite de tolerância de perda de solo. Martins et al. (2003) e Brito et al. (2005) concluíram que os sistemas com eucalipto tiveram valores muito baixos de perda de solo, em relação ao limite de tolerância. Martins et al. (2003) observaram em Argissolo Amarelo a perda de $1,85 \mathrm{Mg} \mathrm{ha}^{-1}$ por ano, em que o limite de tolerância de perda de solo era de $11 \mathrm{Mg} \mathrm{ha}^{-1}$ por ano; e Brito et al. (2005) encontraram perdas de solo de $0,12,0,06$ e $0,10 \mathrm{Mg} \mathrm{ha}^{-1}$ por ano, em plantio de eucalipto em nível sem queima dos restos culturais, e em plantio no sentido do declive com e sem queima, respectivamente. O limite de tolerância de perda para o solo do estudo (Latossolo Vermelho distrófico típico) era de $11,22 \mathrm{Mg}^{-1}$ por ano. Esses resultados evidenciam a adequação do sistema de manejo e a sustentabilidade desses ambientes com cobertura florestal, no contexto da erosão hídrica.

Com exceção de alguns meses, basicamente as perdas de solo acompanharam as perdas de água (Figura 3). Os dados apresentaram coeficientes de correlação positivos de $0,64,0,61$ e 0,54 para $\mathrm{Sd}$, Lavoura e ILF, respectivamente; ou seja, as maiores perdas de água resultaram em maiores perdas de solo, o que indica que o solo erodido depende, com os demais fatores, da quantidade de água escoada. O presente trabalho corrobora os resultados de diversos autores, como Albuquerque et al. (2002), Brito et al. (2005), Guadagnin et al. (2005) e Carvalho et al. (2007) que, apesar de não terem feito a correlação, encontraram na maior parte das análises os maiores valores de perda de solo para os tratamentos que apresentaram as maiores perdas de água.
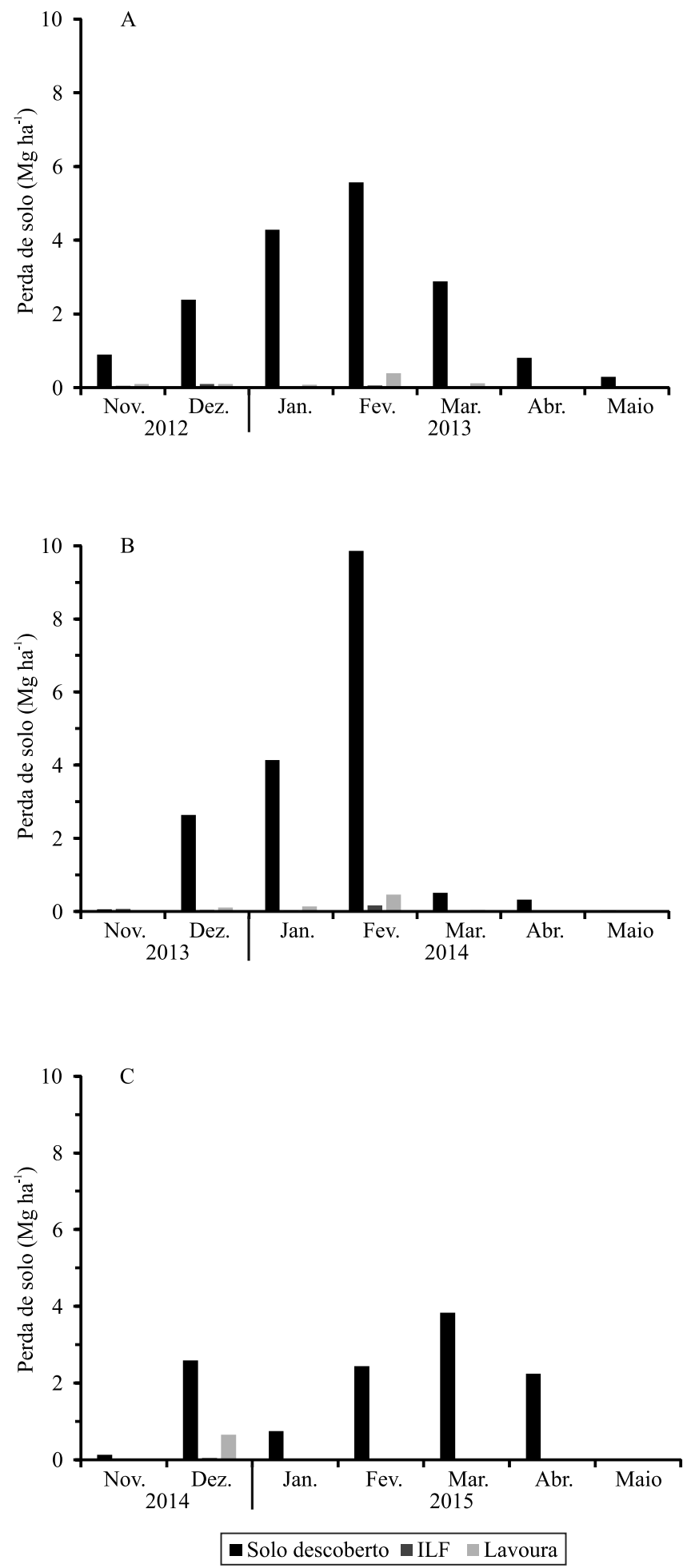

Figura 3. Perda de solo $\left(\mathrm{Mg} \mathrm{ha}^{-1}\right)$ mensal ocorrida em 2012/2013 (A), 2013/2014 (B) e 2014/2015 (C), nos sistemas: ILF, sistema integração lavoura-floresta, lavoura e solo descoberto. 


\section{Conclusões}

1. As perdas de solo por erosão hídrica são influenciadas pelos manejos, mas tanto na integração lavoura-floresta como na sucessão com lavouras de soja-milho, os valores situaram-se abaixo dos limites de tolerância para o Latossolo Vermelho-Amarelo, na região de transição Cerrado/Amazônia.

2. O sistema integração lavoura-floresta apresenta as menores perdas de água e solo, de forma consistente durante todo o período avaliado, e mostram elevado potencial em minimizar a erosão hídrica do solo.

3. A perda de solo apresenta correlação positiva com a perda de água, mas essa inter-relação é menor no sistema de integração lavoura-floresta.

\section{Agradecimentos}

À Embrapa Agrossilvipastoril e ao Conselho Nacional de Desenvolvimento Científico e Tecnológico (CNPq) e à Fundação de Amparo a Pesquisa do estado de Mato Grosso (Fapemat), pelo apoio financeiro.

\section{Referências}

ALBUQUERQUE, A.W.; LOMBARDI NETO, F.; SRINIVASAN, V.S.; SANTOS, J.R. Manejo da cobertura do solo e de práticas conservacionistas nas perdas de solo e água em Sumé, PB. Revista Brasileira de Engenharia Agrícola e Ambiental, v.6, p.136-141, 2002. DOI: $10.1590 /$ S1415-43662002000100024.

ALMEIDA, C.O.S.; AMORIM, R.S.S.; ELTZ, F.L.F.; COUTO, E.G.; JORDANI, S.A. Erosividade da chuva em municípios do Mato Grosso: distribuição sazonal e correlações com dados pluviométricos. Revista Brasileira de Engenharia Agrícola e Ambiental, v.16, p.142-152, 2012. DOI: 10.1590/s141543662012000200003 .

AMARAL, A.J. do; BERTOL, I.; COGO, N.P.; BARBOSA, F.T. Redução da erosão hídrica em três sistemas de manejo do solo em um Cambissolo Húmico da região do Planalto Sul-Catarinense. Revista Brasileira de Ciência do Solo, v.32, p.2145-2155, 2008. DOI: $10.1590 / \mathrm{S} 0100-06832008000500035$.

ARAUJO, R. de A.; COSTA, R.B. da; FELFILI, J.M.; GONÇALVEZ, I.K.; SOUSA, R.A.T. de M. e; DORVAL, A. Florística e estrutura de fragmento florestal em área de transição na Amazônia Matogrossense no município de Sinop. Acta Amazonica, v.39, p.865878, 2009. DOI: 10.1590/S0044-59672009000400015.

BERTOL, I.; COGO, N.P.; LEVIEN, R. Relações da erosão hídrica com métodos de preparo do solo, na ausência e na presença de cobertura por resíduo cultural de trigo. Revista Brasileira de Ciência do Solo, v.11, p.187-192, 1987.

BERTOL, I.; SCHICK, J.; BATISTELA, O. Razão de perdas de solo e fator c para as culturas de soja e trigo em três sistemas de preparo em um Cambissolo Húmico alumínico. Revista Brasileira de Ciência do Solo, v.25, p.451-461, 2001. DOI: 10.1590/S010006832001000200021.

BRITO, L. de F.; SILVA, M.L.N.; CURI, N.; LEITE, F.P.; FERREIRA, M.M.; PIRES, L.S. Erosão hídrica de Latossolo Vermelho muito argiloso relevo ondulado em área de pós-plantio de eucalipto no Vale do Rio Doce, região Centro Leste do estado de Minas Gerais. Scientia Forestalis, v.67, p.27-36, 2005.

CÂNDIDO, B.M.; SILVA, M.L.N.; CURI, N.; BATISTA, P.V.G. Erosão hídrica pós-plantio em florestas de eucalipto na bacia do rio Paraná, no leste do Mato Grosso do Sul. Revista Brasileira de Ciência do Solo, v.38, p.1565-1575, 2014. DOI: 10.1590/S010006832014000500022.

CARVALHO, N. de O.; FILIZOLA JÚNIOR, N.P.; SANTOS, P.M.C. dos; LIMA, J.E.F.W. Guia de práticas sedimentométricas. Brasília: Agência Nacional de Energia Elétrica, 2000. 154p.

CARVALHO, R.; SILVA, M.L.N.; AVANZI, J.C.; CURI, N.; SOUZA, F.S. de. Erosão hídrica em Latossolo Vermelho sob diversos sistemas de manejo do cafeeiro no sul de Minas Gerais. Ciência e Agrotecnologia, v.31, p.1679-1687, 2007. DOI: 10.1590/S1413-70542007000600012.

CONTE, O.; FLORES, J.P.C.; CASSOL, L.C.; ANGHINONI, I.; CARVALHO, P.C. de F.; LEVIEN, R.; WESP, C. de L. Evolução de atributos físicos de solo em sistema de integração lavourapecuária. Pesquisa Agropecuária Brasileira, v.46, p.1301-1309, 2011. DOI: 10.1590/S0100-204X2011001000026.

DIEL, D.; BEHLING, M.;FARIAS NETO,A.L.de; ISERNHAGEN, E.C.C. Distribuição horizontal e vertical de fósforo em sistemas de cultivos exclusivos de soja e de integração lavoura-pecuáriafloresta. Pesquisa Agropecuária Brasileira, v.49, p.639-647, 2014. DOI: 10.1590/S0100-204X2014000800008.

ENGEL, F.L.; BERTOL, I.; MAFRA, Á.L.; COGO, N.P. Water erosion under simulated rainfall in different soil management systems during soybean growth. Scientia Agricola, v.64, p.187193, 2007. DOI: 10.1590/S0103-90162007000200013.

GUADAGNIN, J.C.; BERTOL, I.; CASSOL, P.C.; AMARAL, A.J. do. Perdas de solo, água e nitrogênio por erosão hídrica em diferentes sistemas de manejo. Revista Brasileira de Ciência do Solo, v.29, p.277-286, 2005. DOI: 10.1590/S0100-06832005000200013.

HERNANI, L.C.; KURIHARA, C.H.; SILVA, W.M. Sistemas de manejo de solo e perdas de nutrientes e matéria orgânica por erosão. Revista Brasileira de Ciência do Solo, v.23, p.145-154, 1999. DOI: 10.1590/S0100-06831999000100018.

LANZANOVA, M.E.; ELTZ, F.L.F.; NICOLOSO, R. da S.; CASSOL, E.A.; BERTOL, I.; AMADO, T.J.C.; GIRARDELLO, V.C. Residual effect of soil tillage on water erosion from a Typic Paleudalf under long-term no-tillage and cropping systems. Revista Brasileira de Ciência do Solo, v.37, p.1689-1698, 2013. DOI: 10.1590/S0100-06832013000600025.

LIMA, W. de P. Impacto ambiental do eucalipto. 2.ed. São Paulo: Ed. da USP, 1996. 301p.

LOMBARDI NETO, F.; BERTONI, J. Tolerância de perdas de terra para solos do Estado de São Paulo. Campinas: Instituto Agronômico, 1975. 12p. (IAC. Boletim técnico, 28). 
MARTINS, S.G.; SILVA, M.L.N.; AVANZI, J.C.; CURI, N.; FONSECA, S. Fator cobertura e manejo do solo e perdas de solo e água em cultivo de eucalipto e em Mata Atlântica nos Tabuleiros Costeiros do Estado do Espírito Santo. Scientia Forestalis, v.38, p.517-526, 2010.

MARTINS, S.G.; SILVA, M.L.N.; CURI, N.; FERREIRA, M.M.; FONSECA, S.; MARQUES, J.J.G.S.M. Perdas de solo e água por erosão hídrica em sistemas florestais na região de Aracruz (ES). Revista Brasileira de Ciência do Solo, v.27, p.395-403, 2003. DOI: $10.1590 / \mathrm{S} 0100-06832003000300001$.

OLIVEIRA, V.A. de; MELLO, C.R. de; DURÃES, M.F.; SILVA, A.M. da. Soil erosion vulnerability in the Verde River Basin, southern Minas Gerais. Ciência e Agrotecnologia, v.38, p.262269, 2014. DOI: 10.1590/S1413-70542014000300006.

PANACHUKI, E.; SOBRINHO, T.A.; VITORINO, A.C.T.; CARVALHO, D.F. de; URCHEI, M.A. Parâmetros físicos do solo e erosão hídrica sob chuva simulada, em área de integração agriculturapecuária. Revista Brasileira de Engenharia Agrícola e Ambiental, v.10, p.261-268, 2006. DOI: 10.1590/S1415-43662006000200003.

PIRES, L.S.; BRITO, L.F.; SILVA, M.L.N.; CURI, N.; LEITE, F.P.; BRITO, L. de F. Erosão hídrica pós-plantio em florestas de eucalipto na região centro-leste de Minas Gerais. Pesquisa Agropecuária Brasileira, v.41, p.687-695, 2006. DOI: 10.1590/ S0100-204X2006000400021.
SCHICK, J.; BERTOL, I.; BATISTELA, O.; BALBINOT JÚNIOR, A.A. Erosão hídrica em Cambissolo Húmico alumínico submetido a diferentes sistemas de preparo e cultivo do solo: I. perdas de solo e água. Revista Brasileira de Ciência do Solo, v.24, p.427-436, 2000. DOI: 10.1590/S0100-06832000000200019.

SILVA, A.M. da; SILVA, M.L.N.; CURI, N.; LIMA, J.M. de; AVANZI, J.C.; FERREIRA, M.M. Perdas de solo, água, nutrientes e carbono orgânico em Cambissolo e Latossolo sob chuva natural. Pesquisa Agropecuária Brasileira, v.40, p.1223-1230, 2005. DOI: 10.1590/S0100-204X2005001200010.

SOUZA, A.P. de; MOTA, L.L. da; ZAMADEI, T.; MARTIM, C.C.; ALMEIDA, F.T. de; PAULINO, J. Classificação climática e balanço hídrico climatológico no Estado de Mato Grosso. Nativa, v.1, p.34-43, 2013. DOI: 10.14583/2318-7670.v01n01a07.

WISCHMEIER, W.H. A rainfall index for a universal soil loss equation. Proceedings of The Soil Science Society of America, v.23, p.246-349, 1959. DOI: 10.2136/ sssaj1959.03615995002300030027x.

WOHLENBERG, E.V.; REICHERT, J.M.; REINERT, D.J.; BLUME, E. Dinâmica da agregação de um solo franco-arenoso em cinco sistemas de culturas em rotação e em sucessão. Revista Brasileira de Ciência do Solo, v.28, p.891-900, 2004. DOI: 10.1590/S0100-06832004000500011.

$\overline{\text { Recebido em } 31 \text { de agosto de } 2015 \text { e aprovado em } 21 \text { de dezembro de } 2015}$ 